\title{
ANALYSIS OF MENTAL DISORDERS AND SOCIAL MEDIA ADDICTION OF ADOLESCENT NURSING STUDENTS ON THE BASIS OF GENDER
}

\author{
Kevser Sevgi UNAL ASLAN ${ }^{1}$, Edanur TAR ${ }^{2}$ \\ ${ }^{1}$ Fundamentals of Nursing Department, Osmaniye School of Health, Korkut Ata University,8000, TURKEY \\ ${ }^{2}$ Osmaniye School of Health, Korkut Ata University,8000, TURKEY
}

Address for Correspondence: Assistant.Prof. Kevser Sevgi UNAL ASLAN, E-mail: kevser-sevgi@hotmail.com Received: 23.03.2021; Accepted: 14.04.2021; Available Online Date: 27.05.2021

(C) Copyright 2021 by Dokuz Eylül University, Institute of Health Sciences - Available online at https://dergipark.org.tr/en/pub/jbachs

Cite this article as: Unal-Aslan K.S., Tar E. Analysis Of Mental Disorders And Social Media Addiction Of Adolescent Nursing Students On The Basis Of Gender. J Basic Clin Health Sci 2021; 2: 73- 82.

\begin{abstract}
Objective: The aim of this study is to examine mental disorders and social media addiction in adolescent nursing students in terms of gender.

Methods: The population of this descriptive research was comprised of students of Nursing Department of the Faculty of Health Sciences of a public university in Turkey. Research data were collected via 'Personal Information Form' which addressed socio-demographic characteristics of participants, 'Social Media Addiction Scale (SMA Scale)' and 'Brief Symptom Inventory (BSI)'. Frequencies, means, standard deviations, Kruskal-Wallis test and Mann-Whitney $U$ test were utilized in the analysis of data obtained through the research.

Results: Mean age of students taking part in the research is $19.69 \pm 1.15$. It was found that $51.3 \%$ of students participating in the research were females and smoking was more common among female students. It was ascertained that females had higher means of scores obtained from overall BSI and its anxiety, depression, and negative self-evaluation sub-scales. In light of the finding that the mean of scores obtained by female students from the overall SMA Scale was 77.00 (41-143), it was identified that female students had social media addiction. It was found that there was a statistically significant positive relationship between the mean of scores of overall SMA Scale \& its sub-scales and overall BSI \& its subscales.

Conclusions: Initiatives and activities that can improve students ' mental health and reduce their social media addictions should be planned.

Keywords: Mental disorder, Social media addiction, Adolescent nursing student
\end{abstract}

\section{INTRODUCTION}

Even if internet is a healthy and creative tool which enhances the quality of life and well-being of most people (1) it can give rise to problems as its overuse creates health problems, disturbs daily activities and leads to conflicts with other people (2).There exists no standard definition agreed by all researchers as to what internet addiction is or no standard criteria helping to define what it is about (3). However, there emerged a common conviction that internet addiction came into existence (4).

Shapira et al.(5) defined the problem of internet overuse as the loss of control by the individual over internet use and the case in which this loss of control gave rise to dysfunctionality and disruption in daily life. Griffiths (6) addressed the internet addiction as a 
technological addiction and evaluated technological addiction as a behavioral addiction which was nonchemical and included the interaction of human being and machinery. Moreover, in certain studies, it was deduced that symptoms of internet addiction were in parallel to those observed in social media addiction $(7,8)$.

Internet and social media usage increased at a growing rate especially among youngsters in recent years,(9) and reshaped the lifestyle of children and adolescents (10). Adolescence as a developmental stage is a period in which emotional fluctuations are common, friendships and social environment are important and identity crisis is experienced (11). Factors such as emotional problems, the need for socialization and the search for identity can make internet an attractive instrument for adolescents (12). Internet overuse which is triggered with such emotions and thoughts can turn to be a problem and lead to challenges in individual's life and disturbances in his/her important living spaces by affecting his/her socio-psychological world negatively (13).

Even if there is consensus on the existence of problems associated with the overuse of internet, the number of studies on pathologies accompanying the internet addiction is quite small (14). Researchers argued that internet and social media addiction was in a pretty close relationship with other cases of addiction (15). It is discerned that individuals addicted to internet and social media are more inclined towards problems. Such individuals use internet in order to meet their unsatisfied needs or to express their unvoiced and suppressed emotions $(15,16)$. It is ascertained that certain human beings suffering from depression can attempt to treat depression by focusing on internet and having entertaining activities through internet (17).

Individuals suffering from depression or loneliness can be inclined towards cognitive dissonance. Such people feel good only through internet, and, for them, a world without internet is a terrible place. Therefore, depressive and lonely people feel more fragile in the context of internet and social media addiction (18). As mentioned above, a clear relationship between psychological symptoms and internet \& social media addiction captures the attention. This research was aim for analyzing mental disorders and social media addiction of adolescent nursing students on the basis of gender.

\section{MATERIAL AND METHODS Design}

This research was devised for analyzing mental disorders and social media addiction of adolescent nursing students on the basis of gender.

\section{Sample and setting}

This descriptive and cross-sectional study was carried out from April to June in 2018. Research population was comprised of first-year and secondyear students enrolled at Nursing Department of the Faculty of Health Sciences of a public university in Turkey in the academic year of 2018-2019.

The universe of the research consists of 170 nursing students. In the research, the entire population was selected as the sample prior to the start of the research. However, the research was completed with the participation of 150 students since certain students did not agree to participate in the research or were not within limits of age range specific to adolescents or did not attend the university in the period when the research was conducted.

\section{Data Collection Tools Employed in the Research} Research data were collected from April 20, 2018, to June 15, 2018. The SMA Scale, the BSI and Personal Information Form which contained 18 questions on socio-demographic characteristics of adolescents such as age, gender, education level, marital status and economic level were utilized as data collection tools.

\section{Personal Information Form}

The form includes 18 questions on adolescents' gender, age, education levels of their parents, place of residence, nutritional condition, smoking habit, eating speed and so on.

\section{Brief Symptom Inventory}

BSI is a measurement tool which was developed by Derogatis (19) in order to diagnose psychiatric problems in miscellaneous medical cases and composed of 53 items selected from among 90 items of the Symptom Check List (SCL-90-R) (20). By Şahin and Durak, (21) the BSI was configured for Turkish youth, and its reliability \& validation tests were performed. In reliability tests performed through data sets which were obtained from 3 different samples by 
Şahin and Durak, it was found that Cronbach's Alfa coefficient $(\alpha)$ as the measure of internal consistency ranged from 0.95 to 0.96 for the BSI and from 0.55 to 0.86 for sub-scales of the BSI (20). In our study finding, Cronbach's Alpha value was 0.92 .

\section{Social Media Addiction Scale}

SMA Scale was developed by Van Den Eijnden, Lemmens and Valkenburg in 2016. The Scale was created for diagnosing addiction to internet gaming on the basis of criteria which existed in DSM (Diagnostic and Statistical Manual of Mental Disorders) (22).

SMA Scale is comprised of 41 questions and it is a 5point Likert scale with options of 'Never', 'Rarely', 'Sometimes', 'Frequently' and 'Always'. It was developed by Tutgun, Ünal and Deniz for measuring the social media addiction of university students. All reliability and validation tests for the scale were successfully concluded, and the scale was composed of 41 items and had four factors (preoccupation, mood modification, relapse and conflict) as subscales. Cronbach's Alfa coefficient $(\alpha)$ as the measure of internal consistency was found as 0.967 for the overall scale

In total, the highest score obtained from the scale is 205 whereas the lowest score is 41 . The higher the score is, the higher the social media addiction is. Those with scores ranging from 41 to 73 were categorized as 'not addicted', those with scores ranging from 74 to 106 were categorized as 'a little addicted', those with scores ranging from 107 to 139 were categorized as 'moderately addicted', those with scores ranging from 173 to 205 were categorized as 'highly addicted', and those with scores ranging from 140 to 172 were categorized as 'extremely addicted' (23). In our study, cronbach's Alpha value of the scale was determined as 0.92 .

\section{Collection of Data}

Data were collected through face-to-face interviews. Interviews were performed by the researcher during breaks in classrooms, and, if the break time was not sufficient, the permit to continue the interview was received from course lecturers. Each interview lasted around 15-20 minutes. For carrying out the research, the endorsement was firstly received from the University Ethics Committee, and then, written permit for the collection of data was obtained from the Faculty of Health Sciences. After introducing the research objective and presenting necessary explanations about the research to students, oral approval for participation into the study was received from each student and students volunteering to participate in the research were included in the study.

\section{Evaluation of Data}

All collected data were evaluated through SPSS 18.0 software. In order to analyze the homogeneity of data in the research, One-Sample Kolmogorov-Smirnov Test was applied. In accordance with the rule which required that parametric test would be implemented if test results were $p>0.05$, and nonparametric test would be implemented if test results were $p<0.05$, nonparametric tests were utilized as all variables were $p<0.05$ in this research. In the analysis of data, Kruskal-Wallis (KW) test, Mann-Whitney $U$ test, percentages, means and standard deviations were utilized. Significance level at $5 \%$ was selected for statistical analysis $(p<0.05)$.

\section{Ethical Principles}

Before launching the research, ethical endorsement for performing the research and permit for performing the research at Osmaniye Korkut Ata University were obtained from University Ethics Committee (Ethical Endorsement No: 59754796-050.99/). All individuals participating in the research were informed by the researcher about the topic and in return, they provided the researcher with oral approvals.

\section{Limitations of the Research}

Results of this research can be generalized to students of the nursing department where the research was conducted. Performing the study only with adolescent students of Nursing Department of the Faculty of Health Sciences, failing to reach all members of the population and carrying out the study only at one institution are limitations of this study.

\section{RESULTS}

Upon a closer look at descriptive characteristics of adolescents taking part in the study, it was found that their mean age was $19.69 \pm 1.15$ and $51.3 \%$ of them were females. It was discerned that the mean age of mothers and fathers of female adolescents were successively $46.35 \pm 5.41$ and $50.77 \pm 6.34$, literacy rate of their mothers and fathers were consecutively $44.15 \%$ and $49.35 \%, 54.54 \%$ of them spent most of their lives in the provincial center, $83.11 \%$ of them lived with their families, $84.4 \%$ did not apply to psychiatry service in the past and $58.44 \%$ smoked. It was ascertained that the mean age of mothers and 
fathers of male adolescents were successively $44.92 \pm 5.24$ and $50.02 \pm 5.71,34.24 \%$ of their mothers were secondary school graduates, $34.24 \%$ of their fathers were high school graduates, $82.19 \%$ of them spent most of their lives in the provincial center, $91.78 \%$ of them lived with their families, $93.15 \%$ did not apply to psychiatry service in the past and $47.97 \%$ smoked (Table 1).

Upon the review of sub-scales of overall scales on the basis of gender of adolescents, it was found that there was a statistically significant difference in BSI and its anxiety, depression, negative self-evaluation subscales between females and males $(p<0.05)$.

Upon the review of certain demographic characteristics of adolescents on the basis of gender, it was ascertained that the mean of number of cigarettes smoked by adolescent females was $1.936 \pm .244$ whereas the mean of number of cigarettes smoked by adolescent males was $1.66 \pm .477$, and there was a statistically significant difference in smoking habits between females and males $(p<0.05)$.

Table 1. Breakdown of socio-demographic characteristics of adolescents by gender

Socio-demographic characteristics

$\mathrm{X} \pm \mathrm{SD}$

\begin{tabular}{|c|c|c|c|c|}
\hline \multirow[t]{2}{*}{ Mean Age } & \multicolumn{4}{|c|}{$19.69 \pm 1.15$} \\
\hline & \multicolumn{2}{|c|}{ Female } & \multicolumn{2}{|r|}{ Male } \\
\hline Mean Age of Parents & \multicolumn{2}{|c|}{$\mathrm{X} \pm \mathrm{SD}$} & \multicolumn{2}{|c|}{$\mathrm{X} \pm$ SD } \\
\hline Mean Age of Mothers & \multicolumn{2}{|c|}{$46.35 \pm 5.41$} & \multicolumn{2}{|c|}{$44.92 \pm 5.24$} \\
\hline Mean Age of Fathers & \multicolumn{2}{|c|}{$50.77 \pm 6.34$} & \multicolumn{2}{|c|}{$50.02 \pm 5.71$} \\
\hline & $\mathbf{N}$ & $\%$ & $\mathbf{N}$ & $\%$ \\
\hline Gender & 77 & 51.3 & 73 & 48.6 \\
\hline \multicolumn{5}{|l|}{ Education Level of Mothers } \\
\hline Illiterate & 15 & 19.48 & 7 & 9.58 \\
\hline Literate & 34 & 44.15 & 21 & 28.76 \\
\hline Secondary school graduate & 15 & 19.48 & 25 & 34.24 \\
\hline High school graduate & 10 & 12.98 & 15 & 20.54 \\
\hline University graduate & 3 & 3.89 & 5 & 6.84 \\
\hline \multicolumn{5}{|l|}{ Education Level of Fathers } \\
\hline Illiterate & 7 & 9.09 & 3 & 4.10 \\
\hline Literate & 38 & 49.35 & 10 & 13.69 \\
\hline Secondary school graduate & 12 & 15.58 & 20 & 27.39 \\
\hline High school graduate & 10 & 12.98 & 25 & 34.24 \\
\hline University graduate & 10 & 12.98 & 15 & 20.54 \\
\hline
\end{tabular}

Where did you spend most of your life?

\begin{tabular}{|c|c|c|c|c|}
\hline Province Center & 42 & 54.54 & 60 & 82.19 \\
\hline A District of the Province & 20 & 25.97 & 10 & 13.69 \\
\hline Village & 15 & 19.48 & 3 & 4.10 \\
\hline \multicolumn{5}{|c|}{ Persons with whom you lived for the last 5 years } \\
\hline Parents & 64 & 83.11 & 67 & 91.78 \\
\hline Friends & 1 & 1.29 & 2 & 2.73 \\
\hline Single & - & 0.0 & -0.0 & \\
\hline Dormitory/Institution & 12 & 15.58 & 45.47 & \\
\hline \multicolumn{5}{|c|}{ Did you apply to the psychiatry service in the past? } \\
\hline Yes & 12 & 15.58 & 5 & 6.84 \\
\hline No & 65 & 84.41 & 68 & 93.15 \\
\hline \multicolumn{5}{|l|}{ Do you smoke? } \\
\hline Yes & 45 & 58.44 & 35 & 47.97 \\
\hline No & 32 & 41.55 & 38 & 52.05 \\
\hline
\end{tabular}


Upon a closer look at the relationship between SMA Scale and BSI, it was discerned that there was a statistically significant positive association between means of scores of SMA Scale \& its sub-scales and means of scores of BSI \& its sub-scales $(p<0.05)$. the finding of this study, it is discerned upon the review of literature that males smoked more than females in general (26-28). However, it is argued that smoking rate of females living in developing countries and in the east was higher than that of females living

Table 2. Medians of Scores Obtained from SMA Scale, BSI and their Sub-scales by Gender

\begin{tabular}{|c|c|c|}
\hline & Female & Male \\
\hline & Median(Min-Max) & Median(Min-Max) \\
\hline \multirow[t]{2}{*}{ Anxiety } & $11.00(0-45)$ & $7.500(0-28)$ \\
\hline & $r=1583.0$ & $p=.050$ \\
\hline \multirow[t]{2}{*}{ Depression } & $10.00(0-48)$ & $7.50(0-30)$ \\
\hline & $r=1536.0$ & $p=.036$ \\
\hline \multirow[t]{2}{*}{ Negative Self Evaluation } & $9.00(0-40)$ & $5.50(0-21)$ \\
\hline & $r=1598.0$ & $p=.022$ \\
\hline \multirow[t]{2}{*}{ Hostility } & $7.00(0-26)$ & $6.00(0-27)$ \\
\hline & $r=1933.0$ & $p=.400$ \\
\hline \multirow[t]{2}{*}{ Somatization } & $6.00(0-19)$ & $5.500(0-19)$ \\
\hline & $r=1698.0$ & \\
\hline \multirow[t]{2}{*}{ Overall BSI } & $44.00(0-155)$ & $33.500(0-120)$ \\
\hline & $r=1326.0$ & $p=.048$ \\
\hline \multirow[t]{2}{*}{ Preoccupation } & $24.00(12-55)$ & $23.500(12-68)$ \\
\hline & $r=2097.0$ & $p=.836$ \\
\hline \multirow[t]{2}{*}{ Mood Modification } & $10.00(5-25)$ & $8.500(5-23)$ \\
\hline & $r=1766.0$ & $p=.100$ \\
\hline \multirow[t]{2}{*}{ Relapse } & $9.00(5-25)$ & $9.500(5-47)$ \\
\hline & $r=2047.0$ & $p=.613$ \\
\hline \multirow[t]{2}{*}{ Conflict } & $31.00(19-58)$ & $29.00(19-74)$ \\
\hline & $r=1842.0$ & $p=.216$ \\
\hline Overall SMA Scale & $77.00(41-143)$ & $73.500(41-167)$ \\
\hline
\end{tabular}

\section{DISCUSSION}

In this part, findings obtained from this study which was performed for analyzing mental disorders and social media addiction of adolescent nursing students on the basis of gender were discussed in light of the relevant literature. It is thought that social media addiction of students taking part in the study went up as they spent most of their lives in provincial center, their parents were relatively young on the basis of age averages and had low literacy rates $(24,25)$. It was found that there was a statistically significant relationship between smoking habit of adolescent individuals participating in the study and their gender, and it was deduced that smoking was more common among female adolescents (Table 3 ). In contrast to in developed countries and in the west (29). It is believed that the difference in findings between this study and studies available in the literature pertains to that the sample of this study is composed of adolescents of a developing country and females are more prone to have symptoms of mental disorders. Another reason why mental disorders are seen more in female students may be due to the fact that the number of female students in our study is higher than the number of male students.

Upon the review of the relationship between SMA Scale and BSI and their sub-scales, it was discerned that females had higher means of scores of overall 
Table 3. Analysis of certain demographic characteristics on the basis of gender

\begin{tabular}{|c|c|c|}
\hline & Female & Male \\
\hline & $x \pm S D$ & $x \pm$ SD \\
\hline \multirow[t]{2}{*}{ Did you apply to the psychiatry service in the past? } & $1.87 \pm 3.33$ & $1.84 \pm 3.65$ \\
\hline & & 662 \\
\hline \multirow[t]{2}{*}{$\begin{array}{l}\text { Of the time which you allocate to internet, how long } \\
\text { do you spend on social media websites? }\end{array}$} & $2.30 \pm .882$ & $2.07 \pm .928$ \\
\hline & & 277 \\
\hline \multirow{2}{*}{$\begin{array}{l}\text { On a routine day, how long do you spend on average } \\
\text { by using social networks? }\end{array}$} & $2.30 \pm .460$ & $2.31 \pm .468$ \\
\hline & & .928 \\
\hline \multirow[t]{2}{*}{ Do you see yourself as addicted to social media? } & $1.78 \pm .434$ & $1.76 \pm .426$ \\
\hline & & .875 \\
\hline \multirow[t]{2}{*}{$\begin{array}{l}\text { How many times do you check your profile or } \\
\text { profiles on a common social networking site? }\end{array}$} & $1.99 \pm 1.87$ & $2.15 \pm .1 .136$ \\
\hline & & \\
\hline Do you smoke? & $1.936 \pm .244$ & $1.66 \pm .477$ \\
\hline
\end{tabular}

BSI and its anxiety, depression, and negative selfevaluation sub-scales than males did $(p<0.05)$. Starting from the intrauterine period all thorough childhood, adolescence, adulthood and senility periods, females are more confronted with risk factors than males are. Across the world, females are more vulnerable to stress and negative experiences such as poverty, violence and excessive workload and hence psychological problems are more common among females (30). According to results of different studies, it is demonstrated that, starting from adolescence period, females have depression and anxiety twice or three times as much as males do $(31,32)$. In a study by Bender et al., (33) it was indicated that adolescent females experienced more anxiety and had more trouble in regulating negative feelings than adolescent males did, and hence the risk of having mental disorder was more likely for them than it was for adolescent males. In a largescale study performed with the participation of more than 9,000 individuals in the USA, it was exhibited that females' risk of having any type of mood disorder was one and a half times as much as that of males (34) In a study performed by Avison et al.(35) on adolescents, it was displayed that males had higher self-esteem than females did. The literature supports the finding of this study that adolescent females had mental disorders such as depression, anxiety and self-inferiority more than males did (31-35). It is thought that this situation is likely to arise from the societal gender discrimination which does not value females (36) and stress and anxiety which are experienced by adolescent females due to menstrual cycles, physical modifications and hormonal changes (37).

It was found that the mean of scores obtained from the overall SMA Scale by female students was 77.00 $(41-143)$ whereas the one obtained by male students was 73.500 (41-167) (Table 4). If total score to be obtained from this scale ranged between 41 and 73 , the participant was categorized as 'not addicted to social media', and if it was 74 or above, then the participant was categorized as 'addicted to social media', and in this respect, it was ascertained that female adolescents had social media addiction (Table 2). In the study performed by Rehbein and Mößle (38) in order to analyze the association between video gaming and internet addiction of adolescents, it was demonstrated that females used social media more frequently than males did. In a study conducted by Perrin,(39) it was indicated that females (68\%) used social media more frequently and spent more time on social media during the day than males did $(62 \%)$. Results which are obtained in other studies with respect to the association between social media addiction and gender (40-43) are well-aligned with findings of this study.

As a result of analyses conducted to find out the relationship between SMA Scale and BSI scores of adolescents participating in the study, it was discerned that there was a statistically significant positive association between means of scores of SMA Scale \& its sub-scales and BSI \& its sub-scales (Table 4). In the literature, there exist studies 
Table 4. Correlation Analysis of Scores Obtained from BSI and SMA Scale

\begin{tabular}{|c|c|c|c|c|c|c|}
\hline \multirow{3}{*}{\multicolumn{2}{|c|}{ BSI }} & \multicolumn{4}{|c|}{ SMA Scale } & \multirow[b]{2}{*}{$\begin{array}{c}\text { Overall } \\
\text { Mean of } \\
\text { Scores of } \\
\text { SMA Scale }\end{array}$} \\
\hline & & Preoccupation & $\begin{array}{c}\text { Mood } \\
\text { Modification }\end{array}$ & Relapse & Conflict & \\
\hline & & $\mathbf{r} ; \mathbf{p}$ & $\mathbf{r} ; \mathbf{p}$ & $\mathbf{r} ; \mathbf{p}$ & $\mathbf{r} ; \mathbf{p}$ & $\mathbf{r} ; \mathbf{p}$ \\
\hline \multirow{2}{*}{\multicolumn{2}{|c|}{ Anxiety }} & 0.367 & 0.408 & 0.273 & 0.258 & 0.387 \\
\hline & & $0.000^{* *}$ & $0.000^{* *}$ & $0.001^{\star *}$ & $0.002^{\star *}$ & $0.000^{* *}$ \\
\hline \multirow{2}{*}{\multicolumn{2}{|c|}{ Depression }} & 0.145 & 0.445 & 0.266 & 0.269 & 0.423 \\
\hline & & $0.020^{*}$ & $0.000^{* *}$ & $0.001^{* *}$ & $0.001^{* *}$ & $0.000^{* *}$ \\
\hline Negative & Self- & 0.298 & 0.359 & 0.227 & 0.342 & 0.376 \\
\hline Evaluation & & $0.000^{* *}$ & $0.000^{* *}$ & $0.006^{* *}$ & $0.000^{* *}$ & $0.000^{* *}$ \\
\hline \multirow{2}{*}{\multicolumn{2}{|c|}{ Hostility }} & 0.449 & 0.482 & 0.271 & 0.276 & 0.448 \\
\hline & & $0.000^{* *}$ & $0.000^{* *}$ & $0.001^{* *}$ & $0.001^{* *}$ & $0.000^{* *}$ \\
\hline \multirow{2}{*}{\multicolumn{2}{|c|}{ Somatization }} & 0.215 & 0.299 & 0.176 & 0.262 & ) .2950 .000 \\
\hline & & $0.010^{* *}$ & $0.000^{* *}$ & $0.034^{*}$ & $0.002^{* *}$ & \\
\hline Overall Mean of & & 0.383 & 0.441 & 0.268 & 0.302 & 0.424 \\
\hline Scores of BSI & & $0.000^{* *}$ & $0.000^{* *}$ & $0.002^{* *}$ & $0.000^{* *}$ & $0.000^{* *}$ \\
\hline
\end{tabular}

indicating that internet addiction of adolescent females is accompanied by depression, anxiety, negative self-evaluation and other mental disorders (44-48). Bhagat(16) emphasizes that social media addiction which is centered at the hearth of internet addiction problem is associated with mental health problems such as low self-esteem, anxiety, depression and loneliness. In a study performed by Andreassen et al.(42) for analyzing the relationship of social media addiction with video games and psychiatric disorder symptoms, it was indicated that being female was associated with having social media addiction. In a study conducted by Hong (49) on university students, it was demonstrated that depressive character, negative self-evaluation and feeling of inferiority increased the use of Facebook. Finding of this study which suggests that mental disorders of females give rise to an increase in the use of social media is supported by results of other studies. It is thought that this is likely to stem from the use of social media as a method for coping with stress by adolescent females who more frequently experience mental disorders such as anxiety and depression.
In this study, it was deduced that there was a statistically significant relationship between high mean of scores obtained by female students from anxiety, depression, negative self-evaluation subscales \& overall BSI and female students' social media addiction.

\section{CONCLUSION}

Especially social media addiction and mental disorders in female nursing students draw attention to gender differences. Due to the fact that female students are more exposed to emotional deprivation of during the University, they are introverted and have higher levels of social anxiety, psychological counseling can be applied for female students.

Conflict of interests: The authors declare that there are no conflict of interests.

Author contrıbutıon: KSÜ and ET contributed to conceiving and designing the research. The data were collected, analyzed, and interpreted by KSÜ and ET contributed equally to writing andrevising the manuscript and approved the final manuscript.

Peer-review: Externally peer-reviewed. 


\section{REFERENCES}

1. Arslan G. Psychological maltreatment, forgiveness, mindfulness, and internet addiction among young adults: A study of mediation effect. Computer in Human Behavior 2017;72:57-66.

2. Chou C, Hsiao MC. Internet addiction, usage, gratification, and pleasure experience: the Taiwan college students' case. Computers \& Education, 2000;35(1):65-80.

3. Tao R, Huang X, Wang J, Zhang H, Zhang Y, Li M. Proposed diagnostic criteria for internet addiction. Addiction 2010; 105(3):556-564.

4. Chou C, Hsiao MC. Internet addiction, usage, gratification, and pleasure experience: the Taiwan college students' case. Computers \& Education 2000;35(1):65-80.

5. Shapira NA, Goldsmith TD, Keck PE, Khosla UM, McElroy S L. Psychiatric features of individuals with problematic internet use. Journal of affective disorders 2000;57(1):267-272.

6. Griffiths M. Does internet and computer "addiction" exist? some case study evidence. Cyberpsychology \& Behavıor 2000;3(2):211-218.

7. Andreassen CS. Development of a facebook addiction scale. Psychological Reports 2012;110(2): 501-517.

8. Kuss DJ, Griffiths MD. Online social networking and addiction- a review of the psychological literature. International journal of environmental research and public health 2011;8(9):3528-3552.

9. Johansson A, Götestam G. Internet addiction: characteristics of a questionnaire and prevalence in Norwegian youth (12-18 Years). Scandinavian Journal of Psychology 2004;45:223-229.

10. Kalkan M, Kaygusuz C. Internet addiction. 1 st. Ankara: Anı Publishing, 2013. p.27-35.

11. Steinberg L. Puberty. Figen Çok (Translated Ed). Ankara: İmge Publishing, 2007. p.21.

12. Griffiths M. Sex on the internet: Observations and implications for internet sex addiction. The Journal of Sex Research 2001;38(4):333-342.

13. Shaw $M$, Black DW. Internet addiction. CNS Drugs 2008; 22(5):353-365.

14. Davis RA. A cognitive-behavioral model of pathological internet use. Computers in Human Behavior 200;17:187-195.

15. Young $\mathrm{K}$. What makes the internet addictive. (1997). (Access: http://www.icsao.org/fileadmin/ Divers_papiers/KYoung-internetaddiction4.pdf
16. Bhagat S. Is Facebook alone a planet of individuals? Literature review. International Journal of Indian Psychology 2015;3 (1):5-9.

17. Chou C, Condron LA, Belland JC. Review of the research on internet addiction. Educational Psychology Review 2005; 17(4), 363-388.

18. Yao MZ, Zhong ZJ. Loneliness social contacts and Internet addiction: A cross-lagged panel study. Computers in Human Behavior 2014;30:164-170.

19. Derogatis LR. The Brief Symptom Inventory-BSI administration, scoring and procedures manual-II. USA, Clinical Pscyhometric Research Inc.1992.

20. Sahin $\mathrm{NH}$, Batigun $A D$, Uğurtaş $S$. Short Symptom Inventory (SSI): Validity, Reliability and Factor Structure of Use for Adolescents . Turkish Journal of Psychiatry. 2002;13(2).

21. Şahin Hisli N, Durak A. Brief Symptom Inventory: Its Configuration For Turkish Youth, Turkish Journal Of Psychology 1994;9 (31):44-56

22. Tas I. Validation and Reliability Study for the Short Form of Social Media Addiction Scale for Adolescents. (SMBÖ-KF) Online Journal of Technology Addiction \& Cyberbullying, 2017;4 (1) 27-40.

23. Unal AT. Social Media Addiction: A Research on University Students. PhD Thesis. Marmara University, 2015.

24. Okumuş V, Parlar H. Çocukların Sosyal Medya Kullanım Amaçları Ve Ebeveyn Tutumları. Istanbul Ticaret Üniversitesi Sosyal Bilimler Dergisi. 2018;17(33):357-368.

25. Çelen FK, Çelik A, Seferoğlu SS. nternet usage of children and online risks waiting for them. Academic Informatics. 2011;2:1-8.

26. Reitsma MB, Fullman N, Salama JS, Abajobir A, Akate $\mathrm{KH}$, Abbafati C, Gakidou E. Smoking prevalance and attributable disease burden in 195 countries and territories, 1990- 2015: A systematic analysis from the Global Burden of Disease study. Lancet. 2015;389:1885-1906.

27. Singh T, Arrazola AR, Corey GC, Husten CG, Neff LJ, Homa DM, .King BA. Tobacco use among middle and high school students-United States, 2011- 2015. MMWR. Morbidity and mortality weekly report. Weekly; 2016 / 65(14);361-367.

28. Krishnan-Sarin S, Morean M E, Camenga DR, Cavallo DA, Kong G. E-cigarette use among high school and middle school adolescents in 
Connecticut. Nicotine \& Tobacco Research. 2014;17(7):810-818.

29. Mandil A, BinSaeed A, Ahmad S, Al-Dabbagh R, Alsaadi M, Khan M. Smoking among university students: a gender analysis. Journal of Infection and Public Health.2010;3(4):179-187.

30. World Health Organization. Gender and women's mental health. (Access: 08.12.2019). Retrieved from:

http://www.who.int/mental_health/prevention/gen derwomen.

31. Kessler RC, Avenevoli S, Costello EJ, Georgiades K, Green JG, Gruber MJ, Sampson NA. Prevalence, persistence, and sociodemographic correlates of DSM-IV disorders in the National Comorbidity Survey Replication Adolescent Supplement. Archives of General Psychiatry 2012;69(4):372-380.

32. Wilhelm K, Parker G, Geerligs L, Wedgwood L. Women and depression: a 30 year learning curve. Australian \& New Zealand Journal of Psychiatry. 2008;42(1):3-12.

33. Bender PK, Reinholdt-Dunne ML, Esbjørn BH, Pons F. Emotion dysregulation and anxiety in children and adolescents: Gender differences. Personality and Individual Differences.2012;53(3):284-288.

34. Kessler RC, Berglund $P$, Demler $O$, Jin R, Merikangas KR, Walters EE. Lifetime prevalence and age-of-onset distributions of DSM-IV disorders in the National Comorbidity Survey Replication. Archives of general psychiatry. 2005;62(6):593-602.

35. Avison WR, Mc Alpine DD. "Gender Differences in Symptoms of Depression Among Adolescents", Journal of Health and Social Behavior, 33(2), 1992, ss.77-96; R.L. James, "Correlation Between Adolescent Self-Esteem, Religiosity, and Perceived Family Support", (Access: 24.08.2008). Retrieved from: http://clearinghouse.missouriwestern.edu/manusc ripts/247.asp

36. Hankin BL, Mermelstein R, Roesch L. Sex differences in adolescent depression: Stress exposure and reactivity models. Child Development 2007;78(1):279-295.

37. Thaker R, Verma A. A study of perceived stress and coping styles among mid adolescents. National Journal of Physiology, Pharmacy and Pharmacology 2014;4(1):25.
38. Rehbein F, Mößle T. Video game and Internet addiction: is there a need for differentiation? Sucht, 2013;59(3):129-142.

39. Perrin A. Social networking usage: 20052015. Pew Research Center 2015. Retrieved from:

http://www.pewinternet.org/2015/10/08/2015/Soci al-Networking-Usage-2005-2015/

40. Deniz L, Gürültü E. Social media addiction of high school students. Kastamonu Education Journal 2018; 26(2):355-367.

41. Van Deursen AJ, Bolle CL, Hegner SM, Kommers PA. Modeling habitual and addictive smartphone behavior: The role of smartphone usage types, emotional intelligence, social stress, selfregulation, age, and gender. Computers in human behavior 2015;45:411-420.

42. Andreassen CS, Billieux J, Griffiths MD, Kuss DJ, Demetrovics Z, Mazzoni E, Pallesen S. The relationship between addictive use of social media and video games and symptoms of psychiatric disorders: A large-scale cross-sectional study. Psychology of Addictive Behaviors. 2016; 30(2):252.

43. Kuss DJ, Griffiths MD. Excessive online social networking: Can adolescents become addicted to Facebook? Education and Health 2011;29(4):6366.

44. Li W, O'Brien JE, Snyder SM, Howard MO. Characteristics of internet addiction/pathological internet use in US university students: a qualitative-method investigation. PloS one 2015;10(2):e0117372.

45. Brand M, Young KS, Laier C. Prefrontal control and Internet addiction: a theoretical model and review of neuropsychological and neuroimaging findings. Frontiers in Human Neuroscience. 2014;8:375.

46. Gámez-Guadix M. Depressive symptoms and problematic Internet use among adolescents: Analysis of the longitudinal relationships from the cognitive-behavioral model. Cyberpsychology, Behavior, and Social Networking. 2014;17(11):714-719.

47. Kratzer S, Hegerl U. Is" Internet Addiction" a disorder of its own?--a study on subjects with excessive internet use. Psychiatrische Praxis. 2008; 35(2):80-83.

48. Yen J Y, Ko CH, Yen CF, Wu HY, Yang MJ. The comorbid psychiatric symptoms of Internet addiction: attention deficit and hyperactivity 
disorder (ADHD), depression, social phobia, and hostility. Journal of Adolescent Health. 2007;41(1):93-98.

49. Hong FY, Huang DH, Lin HY, Chiu SL. Analysis of the psychological traits, Facebook usage, and Facebook addiction model of Taiwanese university students. Telematics and Informatics 2014;31(4): 597-606. 